\title{
Hyaluronan synthases (HAS1-3) and hyaluronidases (HYAL1-2) in the accumulation of hyaluronan in endometrioid endometrial carcinoma
}

\author{
Timo K Nykopp ${ }^{1,3}$, Kirsi Rilla ${ }^{2}$, Markku I Tammi ${ }^{2}$, Raija H Tammi ${ }^{2}$ Reijo Sironen ${ }^{1}$, Kirsi Hämäläinen ${ }^{1}$, \\ Veli-Matti Kosma', Seppo Heinonen ${ }^{3}$, Maarit Anttila ${ }^{3^{*}}$
}

\begin{abstract}
Background: Hyaluronan accumulation correlates with the degree of malignancy in many solid tumor types, including malignant endometrial carcinomas. To elucidate the mechanism of hyaluronan accumulation, we examined the expression levels of the hyaluronan synthases (HAS1, HAS2 and HAS3) and hyaluronidases (HYAL1 and HYAL2), and correlated them with hyaluronan content and HAS1-3 immunoreactivity.

Methods: A total of 35 endometrial tissue biopsies from 35 patients, including proliferative and secretory endometrium ( $n=10)$, post-menopausal proliferative endometrium $(n=5)$, complex atypical hyperplasia $(n=4)$, grade $1(n=8)$ and grade $2+3(n=8)$ endometrioid adenocarcinomas were divided for gene expression by realtime RT-PCR, and paraffin embedded blocks for hyaluronan and HAS1-3 cytochemistry.

Results: The mRNA levels of HAS1-3 were not consistently changed, while the immunoreactivity of all HAS proteins was increased in the cancer epithelium. Interestingly, HAS3 mRNA, but not HAS3 immunoreactivity, was increased in post-menopausal endometrium compared to normal endometrium $(p=0.003)$. The median of HYAL1 mRNA was 10 -fold and 15-fold lower in both grade 1 and grade $2+3$ endometrioid endometrial cancers, as compared to normal endometrium ( $p=0.004-0.006)$, and post-menopausal endometrium $(p=0.002)$, respectively. HYAL2 mRNA was also reduced in cancer $(p=0.02)$ and correlated with HYAL1 $(r=0.8, p=0.0001)$. There was an inverse correlation between HYAL1 mRNA and the epithelial hyaluronan staining intensity $(r=-0.6 ; P=0.001)$.

Conclusion: The results indicated that HYAL1 and HYAL2 were coexpressed and significantly downregulated in endometrioid endometrial cancer and correlated with the accumulation of hyaluronan. While immunoreactivity for HASs increased in the cancer cells, tumor mRNA levels for HASs were not changed, suggesting that reduced turnover of HAS protein may also have contributed to the accumulation of hyaluronan.
\end{abstract}

\section{Background}

Cancer of the endometrium is the most common malignant tumor of the female genital tract and it typically affects postmenopausal women $[1,2]$ The prognosis of endometrial cancer is generally good, since the ageadjusted 5-year overall survival is $82 \%$ [3]. Although most patients are diagnosed at an early stage, i.e. disease confined to the uterus, still $20 \%$ of the cancers recur after primary treatment. Adjuvant treatment does not

\footnotetext{
* Correspondence: Maarit.Anttila@uef.fi

${ }^{3}$ Institute of Clinical Medicine, Department of Obstetrics and Gynecology, University of Eastern Finland and Kuopio University Hospital, Kuopio Finland Full list of author information is available at the end of the article
}

prolong the overall survival, maybe because of inadequate patient selection. Therefore, new prognostic markers are needed. Molecular markers in endometrial cancer are still rather poorly defined [4].

It has been commonly recognized that development of human neoplasia is accompanied by changes in the extracellular matrix (ECM) which is particularly important in regulating tumor dissemination [5]. The glycosaminoglycan hyaluronic acid/hyaluronan (HA) is a ubiquitous component of the extracellular matrix (ECM).

Hyaluronan is an independent, unfavorable prognostic factor in another gynaecological malignancy, epithelial ovarian cancer [6], and a number of other 
malignancies $[7,8]$. Hyaluronan and its receptor CD44 are both involved in the development and progression of endometrial cancer [9].

Hyaluronan can be produced in mammals by three hyaluronan synthase isoenzymes: HAS1, HAS2 and HAS3 [10]. HAS mRNA levels often correspond to the rate of hyaluronan synthesis, and are known to influence the content of hyaluronan in transplanted tumors [11]. Therefore, upregulation of HAS expression can contribute to the hyaluronan accumulation in tissues, and promote tumor growth and metastasis in experimental animals, in particular when coexpressed with hyaluronidase $[12,13]$.

The catabolism of hyaluronan is more complex process [14]. Hyaluronan in the extracellular matrix can be partially fragmented by hyaluronidase activity or oxygen free radicals, and diffuse away through lymph. Alternatively, hyaluronan can be taken up by adjacent cells and be subject to lysosomal degradation in the tissue of origin [15]. The rate of hyaluronan catabolism may therefore be contributed by the formation of oxygen free radicals, access to lymph, local uptake by cells, and hyaluronidases.

There are 6 hyaluronidases in the human genome, two of them (HYAL1 and HYAL2) are ubiquitous and characterized at protein level [16]. HYAL1 and HYAL2 have been shown to inhibit tumor growth in vivo, and it has been suggested that these two genes have major roles in the microenvironment of tumor cells [17]. Recent findings have suggested that depending on its concentration, HYAL1 can function either as a tumor promoter or as a suppressor [18].

The major transcript of $H Y A L 3$ is enzymatically inactive and appears to have only a supportive role in $H Y A L 1$ expression [19]. HYAL 3 knockout mice do not display any evidence of hyaluronan accumulation [20]. Very little is known about HYAL4, but its expression is limited, and it might be a chondroitinase rather than hyaluronidase $[16,21]$. The expression of the SPAM1 gene-encoded $\mathrm{PH} 20$ hyaluronidase is almost exclusively detected in testis and sperm, and shows activity in higher $\mathrm{pH}$.

In an invasive bladder cancer cell line, blocking of HYAL1 expression decreases tumor growth, inhibits tumor infiltration and decreases microvessel density [22]. Increased hyaluronidase expression has also been reported in prostate [18] and colon cancer [14], and in breast tumor metastases [23]. In contrast, recent findings have shown that the expression of HYAL1 and HYAL2 genes is significantly decreased in lung and kidney cancer samples [17]. Also experimental overexpression of $H Y A L 1$ in a rat colon carcinoma cell line inhibits tumor growth and generates necrotic tumors [11].

We have found that the median concentration of hyaluronan is increased in malignant ovarian tumors without hyaluronidase activation [24]. In further studies we have shown that significantly decreased HYAL1 expression correlates with decreased hyaluronidase activity and elevated hyaluronan content of the tumors, while $H A S$ expression was not as consistently associated to the accumulation of hyaluronan [25].

In this study we found that in the most common gynaecological malignancy, endometrial cancer, the accumulation of hyaluronan is also associated with decreased expression of hyaluronidase genes. Blocking the accumulation of hyaluronan might offer a new way of fighting against these diseases

\section{Methods}

\section{Patients}

A total of 35 endometrial tissue specimens from 35 patients were divided into 5 groups: proliferative and secretory endometrium $(\mathrm{n}=10)$, post-menopausal proliferative endometrium $(n=5)$, complex atypical hyperplasia $(n=4)$, grade $1(n=8)$ and grade $2+3(n=8)$ endometrioid adenocarcinomas (Table 1 ). The normal endometrium tissue specimens were obtained from hysterectomies for nonmalignant diseases (e.g. leiomyoma or prolapse of uterus). The malignant tumors of endometrium were staged according to FIGO. The ethical committee of the Kuopio University Hospital has approved the study protocol and patients signed the informed consent.

\section{Histology}

Histological typing and grading were done according to the WHO classification [26,27]. Grade 2 and 3 cancers were combined into one subgroup.

\section{Tissue samples}

The tissue specimens collected in the operation room were prepared and evaluated by an experienced pathologist $(\mathrm{KH})$. All the samples were collected and handled identically. Aliquots of the tissues were 1) placed in RNAlater $^{\oplus}$ (Ambion, Austin, TX) for mRNA analyses; 2) fixed in $10 \%$ buffered formalin and embedded in paraffin.

\section{RNA Extraction and cDNA Preparation}

Samples were stored at $-80^{\circ} \mathrm{C}$ until RNA preparation. The samples were frozen by liquid nitrogen and pulverized under pressure using a stainless steel cylinder and a piston. Total RNA was isolated using Trizol $^{\circledR}$ Reagent (Invitrogen) according to manufacturer's protocol, quantified spectrophotometrically and its integrity confirmed by agarose electrophoresis, based on the appearance of the $18 \mathrm{~S}$ and 28S RNA bands. First strand cDNA was synthesized from $2.5 \mu \mathrm{g}$ of total RNA using High-Capacity cDNA Archive kit (Applied Biosystems, Foster City, CA) 
Table 1 Clinicopathological data of the tissue samples

\begin{tabular}{|c|c|c|c|c|c|c|}
\hline \multirow[t]{2}{*}{ Tissue type } & \multirow[t]{2}{*}{ Histology } & \multirow[t]{2}{*}{ No. Patients } & \multirow[t]{2}{*}{ Age at diagnosis ${ }^{\dagger}$} & \multicolumn{3}{|c|}{ FIGO stage } \\
\hline & & & & $\mathrm{IB}$ & IC & $\|$ \\
\hline \multirow[t]{2}{*}{ Normal endometrium } & Proliferating & 4 & $42(42-45)$ & & & \\
\hline & Secreting & 6 & $48(41-52)$ & & & \\
\hline Postmenopausal & Proliferating & 5 & $69(57-75)$ & & & \\
\hline Hyperplastic endometrium & Complex atypical & 4 & $52(45-68)$ & & & \\
\hline \multicolumn{7}{|l|}{ Malignant endometrium } \\
\hline \multirow[t]{3}{*}{ Endometrioid adenocarcinoma } & Grade I & 8 & $66(46-76)$ & 4 & 3 & 1 \\
\hline & Grade II & 4 & $70(63-81)$ & 2 & 1 & 1 \\
\hline & Grade III & 4 & $62(41-81)$ & 1 & 2 & 2 \\
\hline All patients & & 35 & & & & \\
\hline
\end{tabular}

${ }^{\dagger}$ median (range).

according to manufacturer's protocol in a final volume of $50 \mu \mathrm{l}$.

\section{Quantitative real-time RT-PCR}

Real-time gene expression analysis of all target genes (HYAL1, HYAL2, HAS1-3) was performed using TaqMan ${ }^{\circledR}$ Gene Expression Assays (Applied Biosystems) according to manufacturer's instructions and as described previously [25]. The assay numbers for these genes were as follows: Hs00201046_m1 (HYAL1); Hs00186841_m1 (HYAL2); Hs00758053_m1 (HAS1); Hs00193435_m1 (HAS2); Hs00193436_m1 (HAS3); Hs99999909_m1 (HPRT).

The HPRT1 gene we used for normalization was an accurate reference for the quantitative gene expression assays in clinical tumor samples [28]. Relative gene expression values were calculated as the ratio between the target gene and HPRT1, obtained for each sample from the standard curves.

\section{Staining of HASs}

The HAS immunostainings were performed as described previously [25]. Shortly, antigen retrieval was performed for HAS1-3 staining by boiling for $3 \times 5 \mathrm{~min}$ in a citrate buffer. Thereafter sections were treated for $5 \mathrm{~min}$ with $1 \% \mathrm{H}_{2} \mathrm{O}_{2}$ to block endogenous peroxidise activity and incubated in $1 \%$ bovine serum albumin (BSA) in PBS for 30 min to block nonspecific binding. The sections were incubated overnight at $4{ }^{\circ} \mathrm{C}$ with polyclonal antibodies for HAS1 (2 $\mu \mathrm{g} / \mathrm{ml}$, sc-34021, Santa Cruz Biotechnology, inc., Santa Cruz, CA), HAS2 (2 $\mu \mathrm{g} / \mathrm{ml}$, sc-34067, Santa

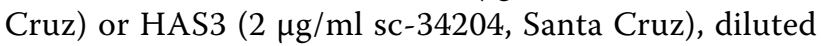
in $1 \%$ BSA. Sections were incubated for 1 hour with biotinylated antigoat antibody (1:1000, Vector Laboratories). The bound antibodies were visualized with the avidinbiotin peroxidase method (1:200, Vectastain Kit, Vector Laboratories), yielding a brown reaction product. The sections were counterstained with Mayer's hematoxylin. The staining intensity of HAS1, HAS2 and HAS3 was graded into three categories in the epithelium: negative (n.d.), weak and moderate, and into two categories in the stroma: negative (n.d.) or weak. The percentage of positive area for each HAS was estimated both in stroma and epithelium.

\section{Staining of Hyaluronan}

Deparaffinized 5- $\mu \mathrm{m}$ tissue sections were stained for hyaluronan with our own preparation of biotinylated hyaluronan-binding complex (bHABC) as described in detail previously [24]. All samples were scored by an observer unaware of the clinical data (M.A.). The intensity of hyaluronan positivity in epithelium and in stroma was graded into three categories: 1 (weak); 2 (moderate); and 3 (strong) and the area percentage of the strongest hyaluronan expression in the whole tumor section was evaluated separately in epithelium and stroma.

\section{Statistical methods}

Statistical analyses were carried out using SPSS 16.0 for Windows (SPSS, Chicago, IL). Differences between the patient groups were first analysed by using a non-parametric Kruskal-Wallis test, and when found significant a non-parametric Mann - Whitney U-test was used for further comparisons between the patient groups. Correlations between gene expression data and hyaluronan staining and immunostaining scores were analysed by using the Spearman's correlation test. A Chi-square test was used to analyse the association of hyaluronan staining and immunostaining scores. We considered p-value $\leq$ 0.01 as statistically significant.

\section{Results}

\section{Expression of HAS1, HAS2 and HAS3}

mRNA from normal endometrium and different tissue lesions were analyzed by real-time RT-PCR for the hyaluronan synthases HAS1, HAS2, and HAS3 (figure 1). Transcripts of HAS1 were detected at such a low level that reliable quantitation was not consistently possible. Expression of HAS2 was not significantly changed in 




malignant tumors or the postmenopausal or hyperplastic tissues as compared to normal endometrium (figure 1A). On the other hand HAS3 expression was increased over 4-fold in post-menopausal endometrium $(\mathrm{p}=0.003)$ compared to pre-menopausal endometrium. We also noticed that HAS3 expression was also elevated (1.5-fold increase) in grade 1 malignant tumors compared to normal endometrium, this finding being borderline significant $(\mathrm{p}=0.033)$ (figure 1B).

\section{Expression of HYAL1 and HYAL2}

Since the two ubiquitous hyaluronidases, HYAL1 and $H Y A L 2$, were likely to account for most or all of the hyaluronidase activity, we quantified their mRNA levels by real-time RT-PCR (figure 2). There was a significant decline in HYAL1 expression from normal endometrium

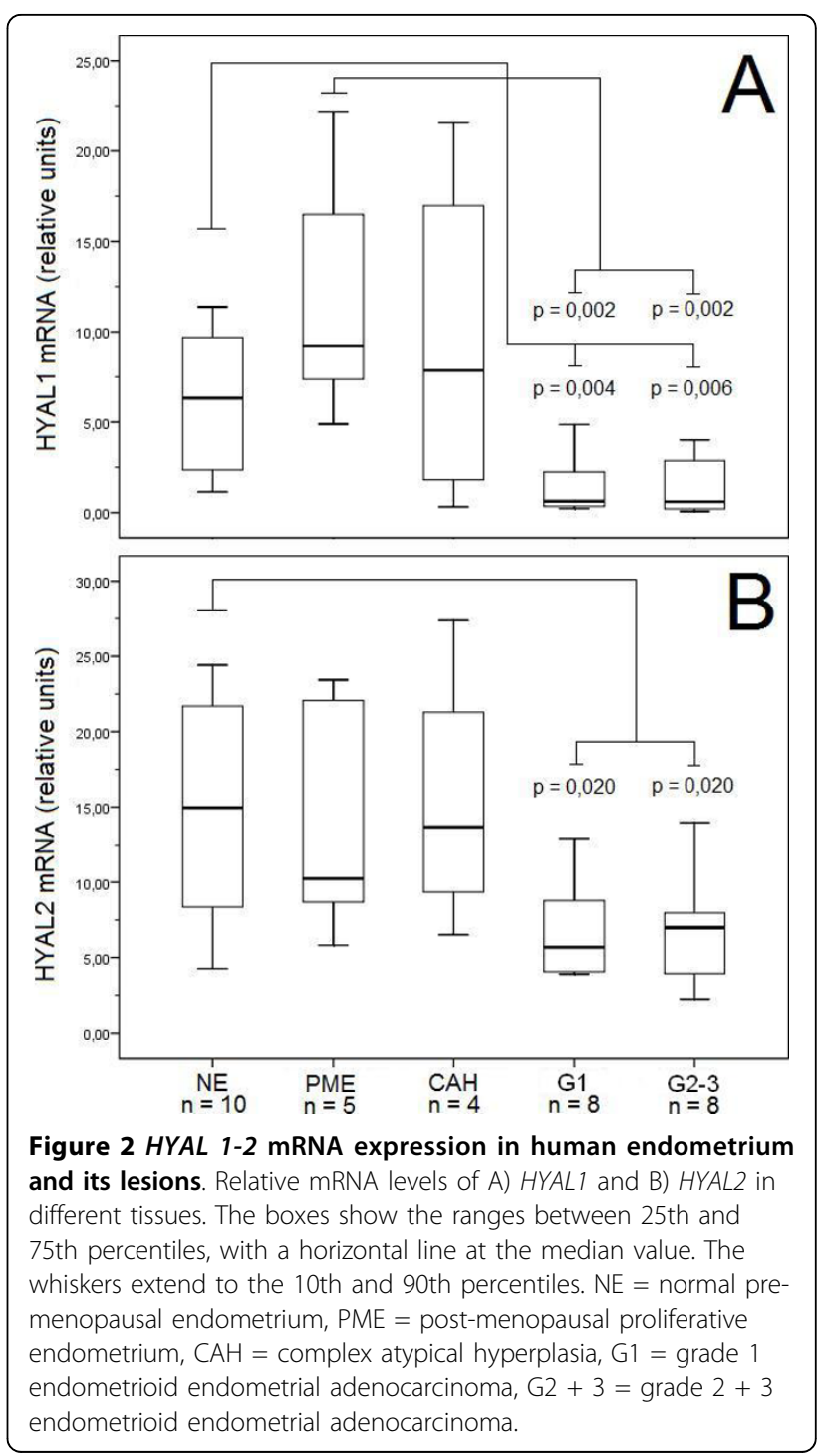

to the cancers (Kruskal Wallis $\mathrm{p}=0.002$ ). A 10-fold higher expression of median HYAL1 mRNA expression was found in normal endometrium as compared to both grade 1 and grade $2+3$ malignant tumors, and over 15 -fold higher values were seen in normal post-menopausal endometrium (figure 2A). Similar trend was noticed between HYAL2 expression in grade 1 and grade $2+3$ cancers compared to normal endometrium, this difference being borderline significant (figure 2B). There was also a strong and statistically significant correlation between HYAL1 and HYAL2 expressions $(\mathrm{r}=0.8 ; \mathrm{p}<0.0001)$

\section{HAS immunostainings}

The epithelial intensities of HAS1 (figure 3A,B), HAS2 (figure 3C,D) and HAS3 (figure 3E,F) immunostainings were significantly stronger in endometrial tumors compared to normal endometrium $(\mathrm{p}=0.001, \mathrm{p}=0.004$ 


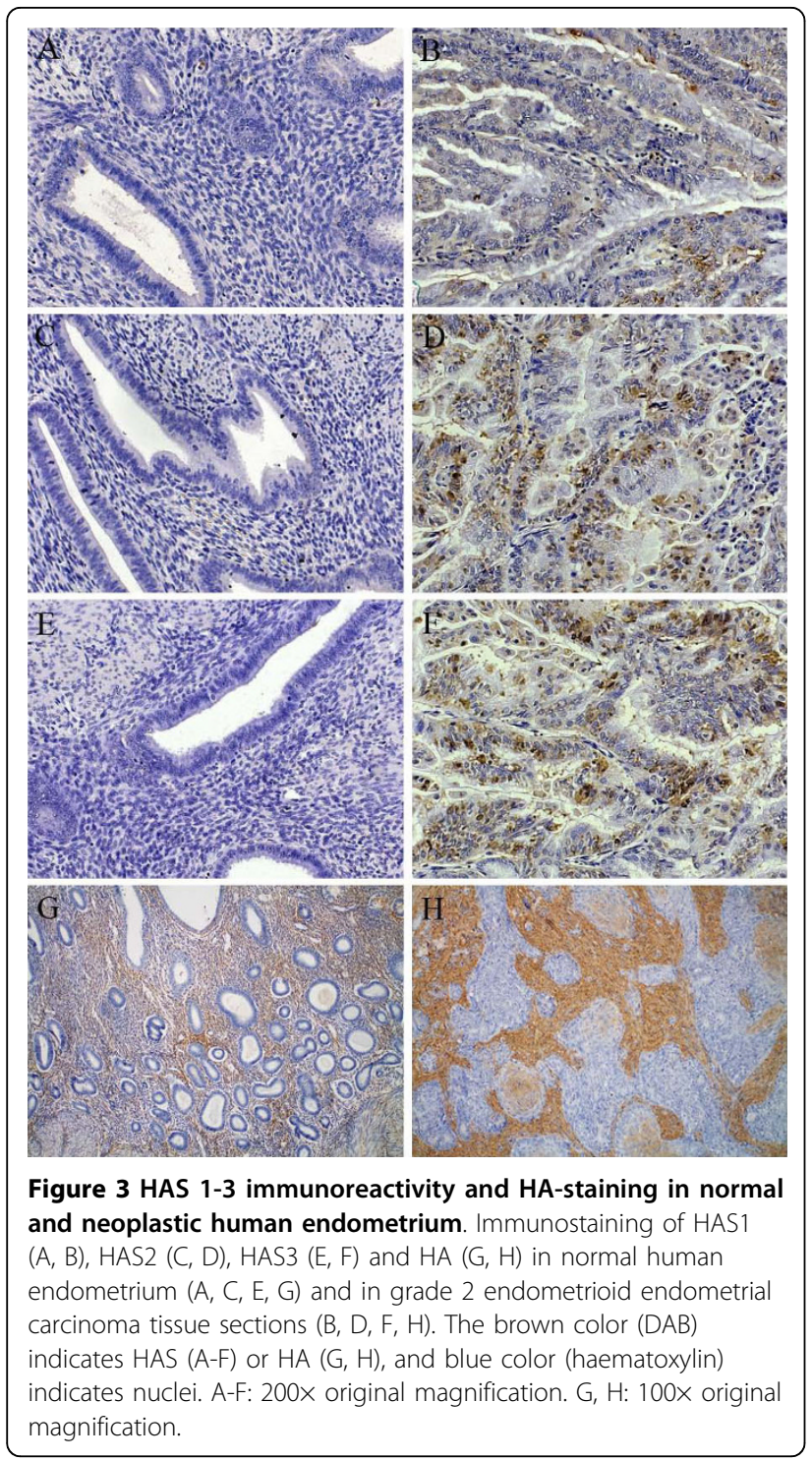

and $\mathrm{p}=0.003$, respectively) (table 2 ). However, the staining intensities did not correlate with tumor grade. Epithelial hyaluronan staining intensity was associated with HAS2 epithelial staining intensity $(p=0.009)$. No significant correlations were found between the mRNA levels and immunohistochemical protein scores of HAS1-3. On the other hand, an inverse correlation of HYAL1 expression with HAS3 epithelial staining intensity was found $(\mathrm{r}=-0.5, \mathrm{p}=0.004)$.

\section{Hyaluronan content}

The level of hyaluronan accumulation in the present set of lesions was scored from tissue sections using a biotinylated probe that specifically binds hyaluronan [6] (figure $3 G, H)$. This histological assay closely correlates with biochemical quantitation of hyaluronan [24]. Epithelial and also stromal hyaluronan intensity score was significantly elevated ( $\mathrm{p}=0.0001$ and $\mathrm{p}=0.006$ respectively) in the endometrioid endometrial tumors compared to normal endometrium (table 3 ).

\section{Relationship between hyaluronan accumulation and HAS and $H Y A L$ mRNA levels}

No significant correlations were found between the level of HAS2 or HAS3 mRNA and the hyaluronan content. Instead, $H Y A L 1$ transcript levels showed a significant inverse correlation with epithelial $(\mathrm{r}=-0.6, \mathrm{p}=0.001)$ and stromal hyaluronan staining score $(\mathrm{r}=-0.4$ $\mathrm{p}=0.01) . H Y A L 2$ transcript levels also correlated with epithelial hyaluronan staining score $(\mathrm{r}=-0.4 \mathrm{p}=0.01)$.

\section{Discussion}

Hyaluronan synthase and hyaluronidase mRNA levels were quantitated for the first time in a set of sample groups from normal endometrium, post-menopausal endometrium, endometrial hyperplasia and endometrioid endometrial tumors.

\section{HAS mRNA expression and immunohistochemistry in endometrioid endometrial cancer}

Except for a trend of HAS3 increase in grade 1 carcinomas, we did not find a clear pattern of increased HAS13 mRNA in endometrial cancer, as compared to normal endometrium. This finding is somewhat similar to the enhanced HAS3 mRNA level observed in benign, but not in malignant ovarian tumors [25]. On the other hand, HAS3 mRNA was increased in proliferating postmenopausal endometrium, and has been suggested to promote the growth of bladder carcinoma cells [29]. Nevertheless, our results suggested that transcriptional upregulation of $H A S$ gene expression was not the main contributor to the increased hyaluronan content of these tumors.

Despite minor changes in mRNAs, the immunoreactivity for all HASs was stronger in cancer cells compared to normal endometrium, although the density of the stainings did not significantly correlate with tumor grade. A similar discordance between the levels of $H A S$ mRNA and HAS immunoreactivity was earlier found in ovarian cancer [25]. Curiously, the statistical significance for the cancer-associated increase of HAS immunoreactivity was strongest for HAS1 although real-time RTPCR suggested very low transcription of this gene. As in the present study, Yabushita et al. [30] found that HAS1 immunoreactivity showed a strong association with endometrial cancer.

$H A S 2$ is the only $H A S$ gene which deletion causes a clear (lethal) phenotype [31], and it has been suggested to be most important for hyaluronan synthesis. In line with this idea, the immunohistochemical signal of 
Table 2 Immunostaining of HAS1, HAS2 and HAS3 in human endometrium and its lesions

\begin{tabular}{|c|c|c|c|c|c|c|c|c|c|c|c|c|c|c|c|}
\hline & \multicolumn{5}{|c|}{$\begin{array}{l}\text { HAS1 } \\
\text { staining } \\
\text { intensity* }\end{array}$} & \multicolumn{5}{|c|}{$\begin{array}{l}\text { HAS2 } \\
\text { staining } \\
\text { intensity* }\end{array}$} & \multicolumn{5}{|c|}{$\begin{array}{l}\text { HAS3 } \\
\text { staining } \\
\text { intensity* }\end{array}$} \\
\hline & \multicolumn{3}{|c|}{ Epithelium } & \multicolumn{2}{|c|}{ Stroma } & \multicolumn{3}{|c|}{ Epithelium } & \multicolumn{2}{|c|}{ Stroma } & \multicolumn{3}{|c|}{ Epithelium } & \multicolumn{2}{|l|}{ Stroma } \\
\hline & n.d. & weak & moderate & n.d. & weak & n.d. & weak & moderate & n.d. & weak & n.d. & weak & moderate & n.d. & weak \\
\hline Normal $n=10$ & 4 & $2(10-25 \%)$ & $4(10-50 \%)$ & 7 & $3(5-50 \%)$ & 7 & 3 (5-10\%) & 0 & 8 & $2(25 \%)$ & 5 & $5(10-20 \%)$ & 0 & 9 & $1(10 \%)$ \\
\hline Proliferating $\mathrm{pm}^{\dagger} \mathrm{n}=5$ & 5 & 0 & 0 & 5 & 0 & 5 & 0 & 0 & 1 & $4(5 \%)$ & 5 & 0 & 0 & 5 & 0 \\
\hline Hyperplasia \# $n=4$ & 1 & $3(5-25 \%)$ & 0 & 3 & $1(10 \%)$ & 1 & $2(10-25 \%)$ & $1(50 \%)$ & 3 & $1(10 \%)$ & 2 & $2(10 \%)$ & 0 & 3 & $1(25 \%)$ \\
\hline Grade $1^{\ddagger} n=8$ & 0 & $5(5-50 \%)$ & $3(25-50 \%)$ & 6 & $2(5 \%)$ & 2 & $5(5-25)$ & $1(50 \%)$ & 8 & 0 & 3 & $3(5-25 \%)$ & $2(25-50 \%)$ & 8 & 0 \\
\hline Grade $2+3^{\ddagger} n=8$ & 0 & $2(25-50 \%)$ & $6(5-50 \%)$ & 8 & 0 & 0 & $5(5-50 \%)$ & $3(5-50)$ & 7 & $1(5 \%)$ & 0 & $3(10-20 \%)$ & $5(10-25 \%)$ & 8 & 0 \\
\hline
\end{tabular}

* num. of samples with \% of positive cells (\% in median; range when necessary).

n.d. = not detected/negative.

\# complex atypical hyperplasia.

${ }^{\dagger} \mathrm{pm}=$ post-menopausal.

‡ endometrioid endometrial adenocarcinoma. 
Table 3 Hyaluronan staining in human endometrium and its lesions

\begin{tabular}{|c|c|c|c|c|c|c|c|c|}
\hline & \multirow{2}{*}{\multicolumn{4}{|c|}{$\begin{array}{l}\text { HA-staining } \\
\text { intensity } \\
\text { Epithelium* }\end{array}$}} & \multirow{2}{*}{\multicolumn{4}{|c|}{$\begin{array}{l}\text { HA-staining } \\
\text { intensity } \\
\text { Stroma* }\end{array}$}} \\
\hline & & & & & & & & \\
\hline & n.d. & weak & moderate & strong & n.d. & weak & moderate & strong \\
\hline Normal $n=9$ & 9 & 0 & 0 & 0 & 0 & 0 & 9 (60\%; 10-90\%) & 0 \\
\hline Proliferating $\mathrm{pm}^{\dagger} \mathrm{n}=5$ & 5 & 0 & 0 & 0 & 0 & 3 & $1(30 \%)$ & $1(100 \%)$ \\
\hline Hyperplasia \# $\mathrm{n}=2$ & 0 & $1(5 \%)$ & $1(40 \%)$ & 0 & 0 & $1(40 \%)$ & 0 & $1(30 \%)$ \\
\hline Grade $1^{\ddagger} n=8$ & 1 & 0 & $5(2-5 \%)$ & $2(5-10 \%)$ & 0 & 0 & 5 (70\%; 20-80\%) & $3(80 \% ; 50-100 \%)$ \\
\hline Grade $2+3^{\ddagger} \mathrm{n}=8$ & 1 & 0 & $4(15 \% ; 10-60 \%)$ & $3(30 \% ; 20-30 \%)$ & 0 & 0 & $2(50-80 \%)$ & $6(80 \% ; 20-90 \%)$ \\
\hline
\end{tabular}

* num. of samples with \% of positive cells (\% in median; range when necessary).

n.d. = not detected/negative.

\# complex atypical hyperplasia.

${ }^{\dagger} \mathrm{pm}=$ post-menopausal.

‡ endometrioid endometrial adenocarcinoma.

epithelial HAS2 correlated with the staining score of epithelial HA.

Since the $H A S$ gene expressions in tumor tissues poorly correlated with the content of the respective HAS proteins, as suggested by immunocytochemistry, the turnover of the HAS proteins should become slower in cancer cells. The time of functional work life of the HAS proteins in tissues was not known, but if extended, it may have had a major influence on hyaluronan synthesis.

\section{Decreased expression of HYAL1 and HYAL2 mRNA and association to hyaluronan accumulation}

The present findings of decreased HYAL1 and HYAL2 mRNA in endometrial cancer are consistent with the results we have recently shown in ovarian cancer [25]. Our findings are also similar to those of lung and kidney cancer samples in which a major down-regulation of HYAL1 and HYAL2 genes has been shown [17]. Our findings in endometrial and ovarian cancer are in contrast to reports on prostate and bladder tumors in which increased HYAL1 protein and mRNA expression is associated with advanced disease and unfavorable prognosis $[32,18,22]$. One hypothesis to solve this contradiction between different types of cancers is that malignancies arising from different cell types use different strategies to progress and evolve. The relative importance of the opposite roles of hyaluronidase function in a particular type of cancer probably determines the outcome. The expression level is also important since HYAL1 can either promote or suppress malignant growth in a single cell type, depending on the resulting enzyme activity [18].

\section{HYAL1, a tumor suppressor}

HYAL1 and HYAL2 genes are located in 3p21.3 chromosome region, where allelic imbalance is frequent $[33,14]$. In the present study we noticed a strong correlation between HYAL1 and HYAL2 mRNA expression. It is possible that in endometrial cancer the $H Y A L$ mRNA expression depends on the status of the chromosome $3 \mathrm{p} 21.3$ locus, and the decreased expression of HYAL1 and HYAL2 may be explained by concomitant deletions of these closely mapped genes. One theory to explain why decreased expression of hyaluronidase genes could lead to the development of cancer is HYAL1 and its role in apoptosis. High HYAL1 activity can result in apoptosis by increasing the expression of WOX1 (WW domain-containing oxidoreductase, WWOX) [22]. WOX1 causes mitochondrial permeabilization and is an essential partner of p53 in cell death [34]. Hyaluronidase can also cause apoptosis by inducing NAD+-linked 15-hydroxyprostaglandin dehydrogenase (15-PDGH), an enzyme that degrades prostaglandins and promotes apoptosis in lung carcinoma cells [35]. Furthermore, the high molecular mass hyaluronan that occupies cell surface CD44 receptors maintains p-Akt and PI3K dependent signals that prevent cancer cell apoptosis, while hyaluronidase, and the oligosaccharides created by hyaluronidase, block these cell survival signals [36]. It has also been recently demonstrated that ectopic expression of all three different somatic hyaluronidases (HYAL1, HYAL2 and HYAL3) induce granulosa cell apoptosis [37].

\section{Conclusion}

The results indicated that HYAL1 and HYAL2 were coexpressed and significantly downregulated in endometrioid endometrial cancer and correlated with the accumulation of hyaluronan. The expression of HAS1-3 $m R N A$ is not elevated in endometrioid endometrial cancer while their immunoreactivity is elevated, suggesting cancer-associated changes in HAS protein turnover.

\section{Abbrevations}

HYAL: hyaluronidase; HAS: hyaluronan synthase; FIGO: International Federation of Gynecologists and Obstetrics. 


\section{Acknowledgements}

We thank Mrs. Helena Kemiläinen, Mrs. Eija Rahunen and Mr. Kari Kotikumpu for expert technical assistance

This work was supported by grants from The Academy of Finland (MT), Finnish Cancer Foundation (RT, V-MK), The Finnish Cancer Institute (MA), The Finnish Medical Foundation (MA) and EVO Funds of the Kuopio University Hospital (TN, MT, V-MK, MA).

\section{Author details}

${ }^{1}$ Institute of Clinical Medicine, Department of Pathology and Forensic Medicine, University of Eastern Finland and Kuopio University Hospital, Kuopio, Finland. ${ }^{2}$ Institute of Biomedicine, Department of Anatomy, University of Eastern Finland, Kuopio, Finland. ${ }^{3}$ Institute of Clinical Medicine, Department of Obstetrics and Gynecology, University of Eastern Finland and Kuopio University Hospital, Kuopio Finland.

\section{Authors' contributions}

TN performed the RNA extraction and RT-QPCR analyses, performed statistical analyses and drafted the manuscript. KR analysed the HAS staining and contributed to the manuscript. MT participated in design of the study and helped to draft the manuscript. $\mathrm{KH}$ contributed to pathological analysis of the tissue samples and helped to draft the manuscript. RT, RS, V-MK, and $\mathrm{SH}$ participated in design of the study and helped to draft the manuscript. MA conceived of the study, and participated in its design and coordination and helped to draft the manuscript.

All authors read and approved the final manuscript.

\section{Competing interests}

The authors declare that they have no competing interests.

Received: 10 May 2010 Accepted: 27 September 2010

Published: 27 September 2010

\section{References}

1. Connelly PJ, Alberhasky RC, Christopherson WM: Carcinoma of the endometrium. III. Analysis of 865 cases of adenocarcinoma and adenoacanthoma. Obstet Gynecol 1982, 59:569-575.

2. Landis SH, Murray T, Bolden S, Wingo PA: Cancer statistics, 1999. CA Cancer J Clin 1999, 49:8-31, 1.

3. Parkin DM, Bray F, Ferlay J, Pisani P: Global cancer statistics, 2002. CA Cancer J Clin 2005, 55:74-108.

4. Engelsen IB, Akslen LA, Salvesen HB: Biologic markers in endometrial cancer treatment. APMIS 2009, 117:693-707.

5. Gui GP, Puddefoot JR, Vinson GP, Wells CA, Carpenter R: Altered cell-matrix contact: a prerequisite for breast cancer metastasis? Br J Cancer 1997, 75:623-633.

6. Anttila MA, Tammi RH, Tammi MI, Syrjanen KJ, Saarikoski SV, Kosma VM: High levels of stromal hyaluronan predict poor disease outcome in epithelial ovarian cancer. Cancer Res 2000, 60:150-155

7. Tammi RH, Kultti A, Kosma VM, Pirinen R, Auvinen P, Tammi Ml: Hyaluronan in human tumors: pathobiological and prognostic messages from cell-associated and stromal hyaluronan. Semin Cancer Biol 2008, 18:288-295.

8. Toole BP, Wight TN, Tammi Ml: Hyaluronan-cell interactions in cancer and vascular disease. J Biol Chem 2002, 277:4593-4596.

9. Afify AM, Craig S, Paulino AF, Stern R: Expression of hyaluronic acid and its receptors, CD44s and CD44v6, in normal, hyperplastic, and neoplastic endometrium. Ann Diagn Pathol 2005, 9:312-318.

10. Weigel PH, Hascall VC, Tammi M: Hyaluronan synthases. J Biol Chem 1997, 272:13997-14000.

11. Jacobson A, Rahmanian M, Rubin K, Heldin P: Expression of hyaluronan synthase 2 or hyaluronidase 1 differentially affect the growth rate of transplantable colon carcinoma cell tumors. Int J Cancer 2002, 102:212-219.

12. Golshani R, Lopez L, Estrella V, Kramer M, lida N, Lokeshwar VB: Hyaluronic acid synthase- 1 expression regulates bladder cancer growth, invasion, and angiogenesis through CD44. Cancer Res 2008, 68:483-491.

13. Bharadwaj AG, Kovar JL, Loughman E, Elowsky C, Oakley GG, Simpson MA Spontaneous metastasis of prostate cancer is promoted by excess hyaluronan synthesis and processing. Am J Pathol 2009, 174:1027-1036.
14. Stern R: Hyaluronan metabolism: a major paradox in cancer biology. Pathol Biol (Paris) 2005, 53:372-382.

15. Tammi R, Rilla K, Pienimaki JP, MacCallum DK, Hogg M, Luukkonen M, Hascall VC, Tammi M: Hyaluronan enters keratinocytes by a novel endocytic route for catabolism. J Biol Chem 2001, 276:35111-35122.

16. Csoka $A B$, Frost $G l$, Stern $R$ : The six hyaluronidase-like genes in the human and mouse genomes. Matrix Biol 2001, 20:499-508.

17. Wang F, Grigorieva EV, Li J, Senchenko VN, Pavlova TV, Anedchenko EA, Kudryavtseva AV, Tsimanis A, Angeloni D, Lerman MI, Kashuba VI, Klein G, Zabarovsky ER: HYAL1 and HYAL2 inhibit tumour growth in vivo but not in vitro. PLoS One 2008, 3:e3031.

18. Lokeshwar VB, Cerwinka WH, Isoyama T, Lokeshwar BL: HYAL1 hyaluronidase in prostate cancer: a tumor promoter and suppressor. Cancer Res 2005, 65:7782-7789.

19. Hemming R, Martin DC, Slominski E, Nagy J, Halayko AJ, Pind S, TriggsRaine B: Mouse Hyal3 encodes a 45- to 56-kDa glycoprotein whose overexpression increases hyaluronidase 1 activity in cultured cells. Glycobiology 2008, 18:280-289.

20. Atmuri V, Martin DC, Hemming R, Gutsol A, Byers S, Sahebjam S, Thliveris JA, Mort JS, Carmona E, Anderson JE, Dakshinamurti S, TriggsRaine B: Hyaluronidase 3 (HYAL3) knockout mice do not display evidence of hyaluronan accumulation. Matrix Biol 2008, 27:653-660.

21. Liu D, Pearlman E, Diaconu E, Guo K, Mori H, Haqqi T, Markowitz S, Willson J, Sy MS: Expression of hyaluronidase by tumor cells induces angiogenesis in vivo. Proc Natl Acad Sci USA 1996, 93:7832-7837.

22. Lokeshwar VB, Cerwinka WH, Lokeshwar BL: HYAL1 hyaluronidase: a molecular determinant of bladder tumor growth and invasion. Cancer Res 2005, 65:2243-2250.

23. Bertrand P, Girard N, Duval C, d'Anjou J, Chauzy C, Menard JF, Delpech B: Increased hyaluronidase levels in breast tumor metastases. Int $J$ Cancer 1997, 73:327-331.

24. Hiltunen EL, Anttila M, Kultti A, Ropponen K, Penttinen J, Yliskoski M, Kuronen AT, Juhola M, Tammi R, Tammi M, Kosma VM: Elevated hyaluronan concentration without hyaluronidase activation in malignant epithelial ovarian tumors. Cancer Res 2002, 62:6410-6413.

25. Nykopp TK, Rilla K, Sironen R, Tammi Ml, Tammi RH, Hamalainen K, Heikkinen AM, Komulainen M, Kosma VM, Anttila M: Expression of hyaluronan synthases (HAS1-3) and hyaluronidases (HYAL1-2) in serous ovarian carcinomas: inverse correlation between HYAL1 and hyaluronan content. BMC Cancer 2009, 9:143.

26. Karseladze Al: WHO histological classification of ovarian tumors, Geneva, 1999. In Arkh Patol Edited by: Scully RE, Sobin LH 2005, , Suppl: 1-64.

27. Tavassoli FA, Devilee P: World Health Organization Classification of Tumours. Pathology \& Genetics of Tumours of the Breast and Female Genital Organs. Lyon: IARC press, 1 2003, 217-232.

28. de Kok JB, Roelofs RW, Giesendorf BA, Pennings JL, Waas ET, Feuth T, Swinkels DW, Span PN: Normalization of gene expression measurements in tumor tissues: comparison of 13 endogenous control genes. Lab Invest 2005, 85:154-159.

29. Liu N, Gao F, Han Z, Xu X, Underhill CB, Zhang L: Hyaluronan synthase 3 overexpression promotes the growth of TSU prostate cancer cells. Cancer Res 2001, 61:5207-5214.

30. Yabushita H, Kishida T, Fusano K, Kanyama K, Zhuo L, Itano N, Kimata K, Noguchi M: Role of hyaluronan and hyaluronan synthase in endometrial cancer. Oncol Rep 2005, 13:1101-1105.

31. Camenisch TD, Spicer AP, Brehm-Gibson T, Biesterfeldt J, Augustine ML, Calabro A Jr, Kubalak S, Klewer SE, McDonald JA: Disruption of hyaluronan synthase-2 abrogates normal cardiac morphogenesis and hyaluronanmediated transformation of epithelium to mesenchyme. J Clin Invest 2000, 106:349-360

32. Kramer MW, Golshani R, Merseburger AS, Knapp J, Garcia A, Hennenlotter J, Duncan RC, Soloway MS, Jorda M, Kuczyk MA, Stenzl A, Lokeshwar VB: HYAL-1 hyaluronidase: a potential prognostic indicator for progression to muscle invasion and recurrence in bladder cancer. Eur Urol 2010 57:86-93.

33. Tuhkanen $H$, Anttila M, Kosma VM, Yla-Herttuala S, Heinonen S, Kuronen A, Juhola M, Tammi R, Tammi M, Mannermaa A: Genetic alterations in the peritumoral stromal cells of malignant and borderline epithelial ovarian tumors as indicated by allelic imbalance on chromosome $3 \mathrm{p}$. Int $J$ Cancer 2004, 109:247-252. 
34. Chang NS, Pratt N, Heath J, Schultz L, Sleve D, Carey GB, Zevotek N: Hyaluronidase induction of a WW domain-containing oxidoreductase that enhances tumor necrosis factor cytotoxicity. J Biol Chem 2001, 276:3361-3370

35. Ding Y, Tong M, Liu S, Moscow JA, Tai HH: NAD+-linked 15hydroxyprostaglandin dehydrogenase (15-PGDH) behaves as a tumor suppressor in lung cancer. Carcinogenesis 2005, 26:65-72.

36. Ghatak S, Misra S, Toole BP: Hyaluronan oligosaccharides inhibit anchorage-independent growth of tumor cells by suppressing the phosphoinositide 3-kinase/Akt cell survival pathway. J Biol Chem 2002, 277:38013-38020.

37. Orimoto AM, Dumaresq-Doiron K, Jiang JY, Tanphaichitr N, Tsang BK, Carmona E: Mammalian hyaluronidase induces ovarian granulosa cell apoptosis and is involved in follicular atresia. Endocrinology 2008, 149:5835-5847.

\section{Pre-publication history}

The pre-publication history for this paper can be accessed here: http://www.biomedcentral.com/1471-2407/10/512/prepub

doi:10.1186/1471-2407-10-512

Cite this article as: Nykopp et al:: Hyaluronan synthases (HAS1-3) and hyaluronidases (HYAL1-2) in the accumulation of hyaluronan in

endometrioid endometrial carcinoma. BMC Cancer 2010 10:512.

\section{Submit your next manuscript to BioMed Central} and take full advantage of:

- Convenient online submission

- Thorough peer review

- No space constraints or color figure charges

- Immediate publication on acceptance

- Inclusion in PubMed, CAS, Scopus and Google Scholar

- Research which is freely available for redistribution

Submit your manuscript at www.biomedcentral.com/submit 